\title{
Delirium treatment in intoxicated patients in ICU: A randomized, double-blind clinical trial
}

\author{
Javad Mesbahi', Shahin Shadnia ${ }^{2}$, Hossein Hassanian-Moghaddam ${ }^{3,1}$, Nasim Zamani ${ }^{3,1}$, Peyman Erfan Talab \\ Evini $^{2}$, Delara Hazegh Fetratjoo ${ }^{4}$, Alireza Kargar ${ }^{5}$, Mitra Rahimi ${ }^{2 *}$
}

'Department of Clinical Toxicology, Loghman Hakim Hospital, Shahid Beheshti University of Medical Sciences, Tehran, Iran ${ }^{2}$ Toxicological Research Center, Excellence Center of Clinical Toxicology, Department of Clinical Toxicology, Loghman Hakim Hospital, Shahid Beheshti University of Medical Sciences, Tehran, Iran

${ }^{3}$ Social Determinants of Health Research Center, Shahid Beheshti University of Medical Sciences, Tehran, Iran

${ }^{4}$ Department of Clinical Pharmacy, School of Pharmacy, Tehran University of Medical Sciences, Tehran, Iran

${ }^{5}$ Student Research Committee, Department of Clinical Pharmacy, School of Pharmacy, Shahid Beheshti University of Medical

Sciences, Tehran, Iran

Received: 17 July 2020

Accepted: 11 October 2020

Published online: 21 October 2020

*Corresponding author:

Mitra Rahimi; Toxicological Research

Center, Excellence Center of Clinical

Toxicology, Department of Clinical

Toxicology, Loghman Hakim

Hospital, Shahid Beheshti University

of Medical Sciences, Tehran, Iran.

Tel/Fax: +98-21-55424041;

Email: mrahimi744@gmail.com

Competing interests: None.

Funding information: None.

Citation: Mesbahi J, Shadnia S, Hassanian-Moghaddam $\mathrm{H}$, Zamani

N, Erfan Talab Evini P, Hazegh

Fetratjoo D, Kargar A, Rahimi M.

Delirium treatment in intoxicated

patients in ICU: A randomized,

double-blind clinical trial. Journal

of Emergency Practice and Trauma

2021; 7(2): 93-96. doi: $10.34172 /$

jept.2020.41

\begin{abstract}
Objective: Delirium is one of the most common complications in patients admitted to intensive care units (ICUs). Delirium is a definite cause for more extended hospital stays, higher mortality rates, and possibly persistent cognitive decline in the future. Antipsychotics have been frequently evaluated as first drugs of choice, but the most appropriate, evidence-based treatment is yet to be discovered. This study aims to compare the efficacy of haloperidol and olanzapine in patients admitted to our toxicology ICU. Methods: This double-blind, randomized controlled clinical trial was undertaken on 35 ICU admitted patients with delirium in Loghman Hakim hospital in Tehran, Iran. The diagnosis was based on the Diagnostic and Statistical Manual of Mental Disorders, Fifth Edition (DSM-V) criteria for delirium, and clinical toxicologists included the patients according to the study's inclusion and exclusion criteria. Patients received either haloperidol or olanzapine based on computerized randomization. The severity of delirium was measured with the Memorial Delirium Assessment Scale (MDAS) scoring on days 0 and 3 of ICUadmission.

Results: The total sample size was 35 in which 16 patients received haloperidol, and 19 patients received olanzapine. The doses of haloperidol and olanzapine were $3 \mathrm{mg}$ three times a day and $5 \mathrm{mg}$ three times a day, respectively. There was no significant difference in baseline characteristics and the scores of MDAS between groups.

Conclusion: Olanzapine and haloperidol have the same efficacy in the management of delirium in toxicology ICU-admitted patients. They can be interchangeably used for delirium treatment in these patients.

Keywords: Delirium, Haloperidol, Olanzapine, Toxicology, Intensive care unit
\end{abstract}

\section{Introduction}

Based on the Diagnostic and Statistical Manual of Mental Disorders, Fifth Edition (DSM-V), delirium is defined as a disturbance in the level of consciousness with reduced ability to direct, focus, sustain or shift attention, which has an abrupt onset with a fluctuating quiddity (1). Delirium has three subtypes: hyperactive, hypoactive, and mixed. Based on previous studies, only the hyperactive subtype of delirium responds to antipsychotic therapy $(2,3)$.

Patients admitted to the intensive care unit (ICU) are susceptible for the development of delirium. Predisposing risk factors include age, gender, baseline physical status, comorbidities such as depression, diabetes, and hypertension, whereas precipitating risk factors include: anemia, hypoxia, fever, electrolyte imbalance, increased levels of bilirubin and creatinine, mechanical ventilation, and medications such as anticholinergics, opiates, benzodiazepines, and steroids (4).

Nearly one-third of ICU admitted patients are diagnosed with delirium, and delirium is associated with more extended hospital stays, higher mortality rates, and a higher risk for the development of cognitive impairments after discharge (5). Among several suggested pathways, acetylcholine deficiency and dopamine excess, also known as the "final common pathway," are the main targeted pathways for pharmacologic treatment of delirium, making antipsychotic agents desirable subjects for research during the past decades (6). Haloperidol, a 
first-generation antipsychotic, has been the drug of choice due to familiarity of use and different available routs of administration (7). The possibility of side effects such as extrapyramidal side effects has drawn the attention of researchers towards second-generation antipsychotics, including olanzapine (8).

Multiple studies have reviewed recent randomized clinical trials and came to a conclusion that, either there is no statistically significant difference between the efficacy of first-generation antipsychotics and second-generation antipsychotics $(9,10)$, or that antipsychotics use has no benefit on delirium and may cause more complications for the patients due to their adverse effects $(11,12)$.

To the best of our knowledge, no studies have evaluated these drugs on delirium in toxicology ICUs. In this study, we aimed to compare the efficacy and tolerability of haloperidol and olanzapine on delirium in patients admitted to the toxicology ICU in Loghman Hakim hospital, which is a referral poisoning center in Iran.

\section{Methods}

Patients with delirium were recruited from December 2019 to May 2020 according to our inclusion and exclusion criteria. The study setting was Loghman Hakim hospital, a referral poisoning center in Iran.

Patients aged 18 and above with no diagnosis of dementia meeting the DSM-V criteria for delirium entered the study. Patients aged above 80 years who were mechanically ventilated, delirious patients due to alcohol intake, patients who were already on antipsychotic medications, patients with a history of hypersensitivity to either haloperidol or olanzapine, and severely agitated patients were excluded from the study. All patients in our study were diagnosed with the hyperactive subtype of delirium.

The severity of delirium was measured using The Memorial Delirium Assessment Scale (MDAS), a tenitem, four-point scale developed to assess delirium in critically ill patients (13). MDAS scores were evaluated at the initial assessment and the third day of ICU admission. Scores of less than 10 indicated an improvement in delirium severity in our study, because the cut-off score of 10 has been proven to have the highest sensitivity for measuring delirium (13).

Our primary outcome was a change in symptoms of delirium based on the MDAS score. Treatment results were evaluated by the researcher on the admission day and three days after.

Demographics of patients and their medical history obtained at the initial assessment included: age, gender, cause of ICU admission, type of drug poisoning, baseline MDAS score, and concomitant medications. We used blocked randomization and sealed envelopes. We selected the drugs, completely blind, by using computerized randomization with Excel $^{\mathrm{Tm}}$ software. We considered the six following blocks: AABB, ABAB, ABBA, BAAB, BABA, and BBAA. Neither the patients nor the nurses knew the type of the prescribed medications.

One group received olanzapine $5 \mathrm{mg}$ tablets, manufactured by Marham Daroo Company, three times a day that were prescribed orally every 8 hours for three days. The other group received haloperidol $3 \mathrm{mg}$ as one 0.5 $\mathrm{mg}$ tablet and half a $5 \mathrm{mg}$ tablet, manufactured by Iran Daroo Company, three times a day that were prescribed orally every 8 hours for up to three days.

For data analysis, we used SPSS software version 26. Frequency, percentages, mean and standard deviation (SD) were calculated for descriptive purposes. Student's t-test and Mann-Whitney U test were used for comparison between the groups.

\section{Results}

Of 35 patients enrolled in our study, 16 patients received haloperidol, and 19 patients received olanzapine. Patient characteristics are shown in Tables 1 and 2. The mean age of patients receiving haloperidol and olanzapine were $38.50 \pm 16.73$ and $37.89 \pm 19.62$ years, respectively. There was no statistically significant difference in the sociodemographic profile and clinical variables between the two groups. Also, poisoning agents between the two groups had no statistically significant difference (Table 3 ).

Mean MDAS score in haloperidol group was 18.00 \pm 3.55

Table 1. Demographic data (qualitative)

\begin{tabular}{|c|c|c|c|c|c|}
\hline \multirow[b]{2}{*}{ Parameter } & \multicolumn{2}{|c|}{ Number } & \multicolumn{2}{|c|}{ Percent } & \multirow[b]{2}{*}{$P$ values } \\
\hline & $\begin{array}{c}\text { Haloperidol } \\
\text { (16) }\end{array}$ & $\begin{array}{c}\text { Olanzapine } \\
\text { (19) }\end{array}$ & Haloperidol & Olanzapine & \\
\hline \multicolumn{6}{|l|}{ Gender } \\
\hline Female & 4 & 5 & 25.0 & 26.3 & \multirow{2}{*}{0.930} \\
\hline Male & 12 & 14 & 75.0 & 73.7 & \\
\hline \multicolumn{6}{|c|}{ Type of poisoning } \\
\hline Intentional & 16 & 19 & 100 & 100 & \multirow{2}{*}{1.000} \\
\hline Accidental & 0 & 0 & 0 & 0 & \\
\hline \multicolumn{6}{|c|}{ Route of poisoning } \\
\hline Oral & 16 & 19 & 100 & 100 & \multirow{4}{*}{1.000} \\
\hline Inhalation & 0 & 0 & 0 & 0 & \\
\hline Skin & 0 & 0 & 0 & 0 & \\
\hline Injection & 0 & 0 & 0 & 0 & \\
\hline
\end{tabular}


Table 2. Demographic data (quantitative) and MDAS rating in the study groups

\begin{tabular}{lcccc}
\hline & \multicolumn{3}{c}{ Mean } & \multicolumn{2}{c}{ Standard Deviation } \\
\cline { 2 - 5 } Parameter & $\begin{array}{c}\text { Haloperidol } \\
\mathbf{( 1 6 )}\end{array}$ & $\begin{array}{c}\text { Olanzapine } \\
\mathbf{( 1 9 )}\end{array}$ & $\begin{array}{c}\text { Haloperidol } \\
\mathbf{( 1 6 )}\end{array}$ & $\begin{array}{c}\text { Olanzapine } \\
\mathbf{( 1 9 )}\end{array}$ \\
\hline Age & 38.50 & 37.89 & 16.73 & 19.62 \\
Length of hospital stay & 13.31 & 11.67 & 8.51 & 6.10 \\
MDAS score & & & 3.55 & 3.93 \\
$\quad$ Baseline & 18.00 & 16.68 & 5.04 & 0.627 \\
$\quad$ Third day & 5.21 & 5.79 & 5.68 & 0.345 \\
\hline
\end{tabular}

Table 3. Poisoning agent(s)

\begin{tabular}{|c|c|c|c|c|c|}
\hline \multirow[b]{2}{*}{ Poisoning agent(s) } & \multicolumn{2}{|c|}{ Number } & \multicolumn{2}{|c|}{ Percentage } & \multirow{2}{*}{$\begin{array}{l}\text { Significant } \\
P \text { values }\end{array}$} \\
\hline & $\begin{array}{l}\text { Haloperidol } \\
\text { (16) }\end{array}$ & $\begin{array}{l}\text { Olanzapine } \\
\text { (19) }\end{array}$ & Haloperidol & Olanzapine & \\
\hline Amphetamine & 1 & 1 & 6.25 & 5.26 & \multirow{20}{*}{0.829} \\
\hline Amphetamine + Methadone & 2 & 0 & 12.50 & 0 & \\
\hline Aluminum Phosphide & 3 & 0 & 18.75 & 0 & \\
\hline Benzodiazepine+ Methylphenidate + alprazolam +methadone & 1 & 0 & 6.25 & 0 & \\
\hline Benzodiazepine + sertraline + biperiden + pimozide & 0 & 1 & 0 & 5.26 & \\
\hline Beta blocker +benzodiazepine & 0 & 1 & 0 & 5.26 & \\
\hline Citalopram +ibuprofen +benzodiazepine +adult cold & 0 & 1 & 0 & 5.26 & \\
\hline Heroin +methadone +benzodiazepine & 0 & 1 & 0 & 5.26 & \\
\hline Metformin & 0 & 1 & 0 & 5.26 & \\
\hline Methadone & 3 & 2 & 18.75 & 10.53 & \\
\hline Methadone +benzodiazepine & 0 & 1 & 0 & 5.26 & \\
\hline Methadone +benzodiazepine +tramadol & 0 & 1 & 0 & 5.26 & \\
\hline Methadone +tramadol & 1 & 1 & 6.25 & 5.26 & \\
\hline Methadone +zolpidem & 0 & 1 & 0 & 5.26 & \\
\hline Methanol & 0 & 5 & 0 & 26.32 & \\
\hline Organophosphate & 1 & 1 & 0 & 5.26 & \\
\hline Tramadol +heroin +marijuana & 0 & 1 & 0 & 5.26 & \\
\hline Tramadol & 1 & 0 & 6.25 & 0 & \\
\hline Opium & 2 & 0 & 12.50 & 0 & \\
\hline $\begin{array}{l}\text { Losartan +haloperidol +sertraline+ risperidone + acetaminophen } \\
\text { codeine + quetiapine+ vitamin D }\end{array}$ & 1 & 0 & 6.25 & 0 & \\
\hline
\end{tabular}

that reached to $5.21 \pm 5$ on the third day of evaluation, and in olanzapine group was $16.68 \pm 3.93$ that reached to $5.79 \pm 5.68$ on the third day. These results show that both groups changed from a "moderate" stage of delirium to "mild" as shown in Figure 1.

No patients showed adverse effects.

All patients were admitted to Loghman Hakim hospital due to intentional poisoning with orally consumed poisons, and there was no statistically significant difference between the two groups in terms of the poisoning agent(s).

\section{Discussion}

Management of delirium in toxicology ICUs is a common issue faced by clinical toxicologists around the world. To our knowledge, this is the first clinical trial conducted on poisoning ICU patients. After considering potential confounders, we found that pharmacotherapy of delirium in the toxicology ICU admitted patients with haloperidol and olanzapine had statistically no significant difference in terms of MDAS score improvement. This finding is in accordance with previous studies on ICU admitted patients that have compared the efficacy of haloperidol as the most prescribed first-generation antipsychotic in the world with second-generation antipsychotics such as olanzapine. In a comparative study conducted by Boettger et al., haloperidol, risperidone, aripiprazole, and olanzapine were equally effective for the treatment of delirium in

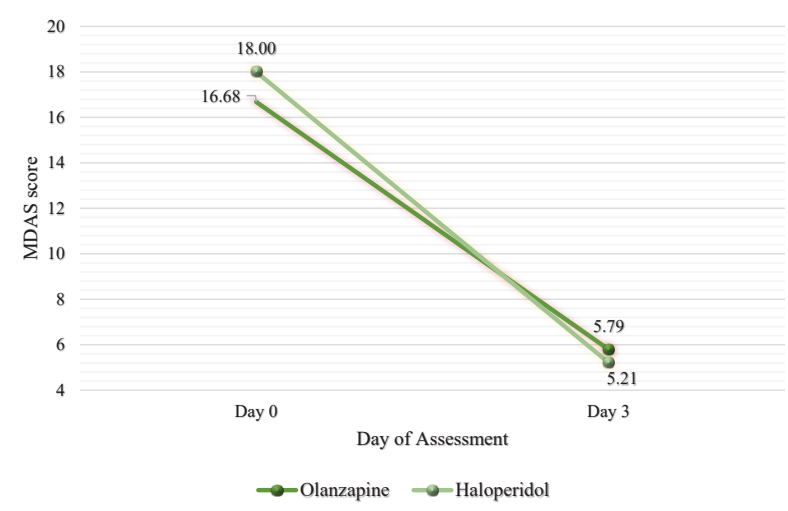

Figure 1. Comparison of MDAS scores on day 0 and 3 of the study. 
critically ill cancer patients (14). An observational study by Yoon et al showed no statistically significant difference in the efficacy of haloperidol, risperidone, olanzapine, and quetiapine (15). In a randomized controlled trial by Grover et al, the efficacy of olanzapine and risperidone were similar to haloperidol (16). A review by Lonergan et al. showed no difference in the efficacy of haloperidol in comparison with olanzapine and risperidone for the management of delirium (17).

The fixed dosages of haloperidol and olanzapine in our study were within the approved therapeutic range but greater than previous studies, suggesting the higher doses of antipsychotics needed for the treatment of delirium in poisoned ICU admitted patients.

For future studies, we recommend the inclusion of larger sample sizes and clinical trials with more than two arms to compare haloperidol and olanzapine with other first or second-generation antipsychotics.

\section{Conclusion}

Based on this study, we conclude that olanzapine is as effective as haloperidol for the management of poisoning ICU delirium. For future researches, we suggest conducting randomized controlled trials with greater sample sizes, dose-ranging studies, evaluation of other assessment tools rather than MDAS, and comparison of multiple secondgeneration antipsychotics.

\section{Ethical issues}

This study was approved by the ethics committee of Shahid Beheshti University of Medical Sciences with the ethics code: IR.SBMU.RETECH.REC.1398.426. Additionally, this study was registered at Iranian Registry of Clinical Trials (identifier: IRCT20190928044909N1; https://www. irct.ir/trial/42569). All patients or caregivers signed the written consent form before being included in our study.

\section{Authors' contribution}

MR participated in the study design and writing of the paper. JM helped in the study design, examination of patients, filling out the checklists as well as data collection. $\mathrm{AK}$ and DHF helped in data analysis and writing of the paper. HHM, NZ, ShSh and, PEE helped in writing the final version of the paper.

\section{Refrences}

1. American Psychiatric Association. Diagnostic and Statistical Manual of Mental Disorders (DSM-5 ${ }^{\circledR}$ ). Arlington, VA: American Psychiatric Association; 2013.

2. Liptzin B, Levkoff SE, Gottlieb GL, Johnson JC. Delirium. J Neuropsychiatry Clin Neurosci 1993; 5(2): 154-60. doi: 10.1176/jnp.5.2.15

3. Cascella M, Fiore M, Leone S, Carbone D, Di Napoli R. Current controversies and future perspectives on treatment of intensive care unit delirium in adults. World J Crit Care Med 2019; 8(3): 18-27. doi: 10.5492/wjccm.v8.i3.18.
4. Jayaswal AK, Sampath H, Soohinda G, Dutta S. Delirium in medical intensive care units: incidence, subtypes, risk factors, and outcome. Indian J Psychiatry 2019; 61(4): 3528. doi: 10.4103/psychiatry.IndianJPsychiatry_583_18.

5. Salluh JI, Wang H, Schneider EB, Nagaraja N, Yenokyan G, Damluji A, et al. Outcome of delirium in critically ill patients: systematic review and meta-analysis. BMJ 2015; 350: h2538. doi: 10.1136/bmj.h2538.

6. Trzepacz PT. Is there a final common neural pathway in delirium? focus on acetylcholine and dopamine. Semin Clin Neuropsychiatry 2000; 5(2): 132-48. doi: 10.153/ scnp00500132.

7. Bush SH, Tierney S, Lawlor PG. Clinical assessment and management of delirium in the palliative care setting. Drugs 2017; 77(15): 1623-43. doi: 10.1007/s40265-017-0804-3.

8. Wang HR, Woo YS, Bahk WM. Atypical antipsychotics in the treatment of delirium. Psychiatry Clin Neurosci 2013; 67(5): 323-31. doi: 10.1111/pcn.12066.

9. Rea RS, Battistone S, Fong JJ, Devlin JW. Atypical antipsychotics versus haloperidol for treatment of delirium in acutely ill patients. Pharmacotherapy 2007; 27(4): 58894. doi: 10.1592/phco.27.4.588.

10. Ozbolt LB, Paniagua MA, Kaiser RM. Atypical antipsychotics for the treatment of delirious elders. J Am Med Dir Assoc 2008; 9(1): 18-28. doi: 10.1016/j.jamda.2007.08.007.

11. Burry L, Mehta S, Perreault MM, Luxenberg JS, Siddiqi N, Hutton B, et al. Antipsychotics for treatment of delirium in hospitalised non-ICU patients. Cochrane Database Syst Rev 2018; 6(6): CD005594. doi: 10.1002/14651858. CD005594.pub3.

12. Barbateskovic M, Krauss SR, Collet MO, Larsen LK, Jakobsen JC, Perner A, et al. Pharmacological interventions for prevention and management of delirium in intensive care patients: a systematic overview of reviews and metaanalyses. BMJ Open 2019; 9(2): e024562. doi: 10.1136/ bmjopen-2018-024562.

13. Breitbart W, Rosenfeld B, Roth A, Smith MJ, Cohen K, Passik S. The memorial delirium assessment scale. J Pain Symptom Manage 1997; 13(3): 128-37. doi: 10.1016/s08853924(96)00316-8.

14. Boettger S, Jenewein J, Breitbart W. Haloperidol, risperidone, olanzapine and aripiprazole in the management of delirium: a comparison of efficacy, safety, and side effects. Palliat Support Care 2015; 13(4): 1079-85. doi: 10.1017/ s1478951514001059.

15. Yoon HJ, Park KM, Choi WJ, Choi SH, Park JY, Kim JJ, et al. Efficacy and safety of haloperidol versus atypical antipsychotic medications in the treatment of delirium. BMC Psychiatry 2013; 13: 240. doi: 10.1186/1471-244x-13240.

16. Grover S, Kumar V, Chakrabarti S. Comparative efficacy study of haloperidol, olanzapine and risperidone in delirium. J Psychosom Res 2011; 71(4): 277-81. doi: 10.1016/j.jpsychores.2011.01.019.

17. Lonergan E, Britton AM, Luxenberg J, Wyller T. Antipsychotics for delirium. Cochrane Database Syst Rev 2007; (2): CD005594. doi: 10.1002/14651858.CD005594. pub2. 